\title{
Thioredoxin level and inflammatory markers in children with autism spectrum disorders
}

\author{
Naglaa A. Abd-Allah', Ola M. Ibrahim², Heba A. Elmalt ${ }^{3}$, Manal A. Shehata², Rania A. Hamed ${ }^{4 *}$ \\ Nisrin M. Elsaadouni $i^{5}$ and Bahaa Hawary ${ }^{6}$
}

\begin{abstract}
Background: Autism Spectrum Disorders (ASD) are a group of neurodevelopmental disabilities with unknown etiology. Recent studies suggest the contribution of immune dysfunction and oxidative stress in its pathophysiology. The present study aimed to investigate the serum level of thioredoxin (Trx), as a marker of oxidative stress and some inflammatory cytokines, and to evaluate their role in children with ASD.

Results: Concentrations of Trx, IL-1 $\beta, I L-8$, and TNF-a were significantly higher in children with ASD compared with matched controls. There were no association between cytokine levels and the severity of clinical manifestations, according to CARS classification of severity.

Conclusion: The present study provides support for the idea that physiological abnormalities, such as oxidative stress and immune dysfunction, may contribute in the pathophysiology of ASD.
\end{abstract}

Keywords: Autism spectrum disorders, Childhood, Cytokines, Immune dysfunction

\section{Background}

Autism spectrum disorders (ASD) are a group of neurodevelopmental disabilities that cause impaired communication and social interactions and narrow patterns of behaviors [1].

The Diagnostic and Statistical Manual of Mental Disorders, 5th edition (DSM-5), provides diagnostic criteria for ASD, which includes Asperger syndrome, classic autism, childhood disintegrative disorder, and pervasive developmental disorders not otherwise specified. Deficits may appear as early as 6-9 months of age, although most manifest during the second year. Reliable diagnosis can be made around age 2; however, many children do not have final diagnosis until much older [2].

Multiple pathological mechanisms implicated in psychiatric diseases including immune dysregulation, inflammatory processes, oxidative stress, environmental contaminants exposures, and mitochondrial dysfunction [3].

\footnotetext{
* Correspondence: drrania96@gmail.com

${ }^{4}$ Psychiatry Department, Faculty of Medicine for Girls, Al-Azhar University, Cairo, Egypt

Full list of author information is available at the end of the article
}

The etiology of ASD is complex and mostly unknown; research suggests interactions between several factors including genetic, epigenetic, and environmental factors [4].

Serum thioredoxin (Trx) level has been suggested as an indicator of oxidative stress, immune dysregulation, and inflammation [5].

These findings indicate that Trx may be involved in the pathogenesis of autism [6].

Dysfunctional immune responses in subjects with ASD have been reported in several studies. Alterations of cytokine activity have been studied in patients of ASD [7-10]. Few of these studies have reported increased levels of cytokines that can precipitate inflammatory processes in ASD, such as interferon gamma (IFNy) or IL-12 [11, 12], or a decreased production of cytokines that negatively regulate inflammation, such as transforming growth factor $\beta 1$ (TGF $\beta 1$ ) [9]. In addition, results of previous reports addressing serum or plasma levels of IL-8 in ASD appear to be inconsistent $[13,14]$.

Role of cytokines in brain development has been reported in several studies; different mechanisms of action were suggested. For instance, tumor necrosis factor 
alpha (TNF- $\alpha$ ) and interleukin-1ß (IL-1ß) are found to have an essential role in neurodevelopment and synaptic pruning $[15,16]$. Moreover, emerging evidence involves cytokines in higher neurological functions, including cognition and memory $[17,18]$. Thus, abnormal inflammatory activity could contribute to behavioral and neurological dysfunction in ASD $[14,19]$.

Therefore, the aim of the present study was to investigate the serum level of thioredoxin and some inflammatory cytokines (IL-1ß, IL- 8 , TNF- $\alpha$ ), and to evaluate their role in children with autism spectrum disorders.

\section{Methods}

A case control study was conducted in the psychiatry outpatient clinic at Al-Azhar University Hospital. Thirty five children with ASD aged from 2 to 10 years were randomly selected.

1. Inclusions criteria

(a) Newly diagnosed children with autism spectrum disorders who are fulfilling the criteria of the Diagnostic and Statistical Manual of Mental Disorders, 5th edition (DSM-5) [20].

(b) Score on childhood autism rating scale (CARs) is above 30 [21].

2. Exclusion criteria

(a) Children with another psychiatric disorder (e.g., ADHD, anxiety, depression)

(b) Children with other causes of intellectual disability, other causes of language impairment

(c) Children with chronic medical co-morbid condition

(d) Children with proved genetic, metabolic, or neurologic etiology for autistic disorder

(e) Children receiving antioxidants

Another 35 apparently healthy children with matched age and sex were recruited from the outpatient clinic at Al-Azhar University Hospital and served as a control group. They were the siblings of the children attending this clinic because of a minor illness. The control children were not related to the children with ASD, and demonstrated no clinical findings suggestive of infections, allergic manifestations, and immunological or neuropsychiatric disorders.

\section{Ethical considerations}

The study protocol was approved by the institution ethical review board (medical research ethics committee at National Research Centre, Cairo, Egypt), according to Helsinki Declaration 1975 revised in 2008.

Written informed consent was obtained from all parents of both patients and control groups before getting them involved in the study. They were informed by the aim and potential benefits of the study.

All studied children were subjected to the following:

1. Thorough history taking including:

(a) Personal data: age, sex, and residence

(b) Prenatal history: Parental age at birth (maternal and paternal), maternal diseases (as diabetes mellitus, hypertension, epilepsy, depression, infections), and maternal drug therapy (as hormonal, antiepileptic, anti-hypertensive, or antipsychotic drugs)

(c) Natal and postnatal history as gestational age at birth, birth weight, mode of delivery, and birth order

2. Thorough clinical examination which included meticulous general and specific systemic examination.

3. Clinical diagnosis of ASD was based on the criteria for autistic disorder as defined in the DSM-5.

4. Assessment of autism severity using Childhood autism rating scale (CARS): The CARS is a 15-item behavioral rating scale developed to identify autism as well as to quantitatively describe the severity of the disorder [22]. The examiner assigned scores between 1 and 4 for each domain: 1 indicates normal behavior appropriate for age level (no signs of autism), while 4 indicates a severe deviance with respect to the normal behavior (severe symptoms of autism). The scores for the single items are added together into a total score. The maximum CARS score is 60 , and the cutoff for autism is 30 [21, 23].

Accordingly, patients with ASDs were classified into three groups:

a. Mild cases group: their (CARS) score ranging from 30 to $<33$

b. Moderate cases group: their (CARS) score ranging from 33 to $<37$

c. Severe cases group: their (CARS) score at or above 37 
5. Anthropometric assessment: Weight, height, and BMI were expressed as weight-for-age Z-score (WAZ), height-for-age Z-score (HAZ), and BMI-Zscore (BAZ) after being calculated according to the WHO standards using the Anthro Plus software of WHO (2009) [24].

6. Laboratory investigations:

(a) Complete blood picture was done automatically by EPX MICRO 60 automated hematological counter.

(b) Five milliliters of venous blood were collected and delivered into a tube and were allowed to clot and after centrifugation, sera were separated and stored frozen at $-20^{\circ} \mathrm{C}$ after careful labeling till the time of assay.

(c) Quantitative determination of serum thioredoxin (Trx), Interleukein $1 \beta$ (IL-1 $\beta$ ), IL8, and tumor necrosis factor $\alpha$ (TNF $\alpha$ ) concentration were done using ELISA technique. Kits were delivered by INOVA.

\section{Principle of the assay}

This ELISA kit uses Sandwich-ELISA as the method. The Micro Elisa strip plate provided in this kit has been pre-coated with an antibody specific to thioredoxin (Trx), IL-1ß, IL8, and TNF $\alpha$ standards, or samples are added to the appropriate Micro Elisa strip plate wells and combined to the specific antibody. Then, a horseradish peroxidase (HRP)-conjugated antibody specific for Trx, IL-1ß, IL8, TNF- $\alpha$ is added to each Micro Elisa strip plate well and incubated.

Free components are washed away. The TMB substrate solution is added to each well. Only those wells that contain Trx and HRP conjugated Trx antibody will appear blue in color and then turn yellow after the addition of the stop solution. The optical density (OD) is measured spectrophotometrically at a wave length of $450 \mathrm{~nm}$. The OD value is proportional to the concentration of Trx, IL-1ß, IL8, and TNF- $\alpha$ concentration of Trx in the samples can be calculated by comparing the $\mathrm{OD}$ of the samples to the standard curve [25].

\section{Statistical analysis}

Data were analyzed using the statistical package for social science (SPSS). Computer software package SPSS 16.0 was used in the analysis. For quantitative variables, mean, standard deviation, minimum, and maximum (as measures of variability) were presented. ANOVA, Independent $t$, Mann-Whitney, and Kruskal Wallis tests were used to estimate differences in quantitative variables. Spearman's rank correlation test was used to determine the relationship between different numerical variables.
For all tests, probability values $(p)$ of less than 0.05 were regarded as statistically significant.

\section{Results}

This study was conducted on 35 children with autism spectrum disorders (ASD); 24 males and 11 females with age ranging from 2 to10 years (mean age $=4.7 \pm 2.4$ years), 10 of them were mild ASDs, 16 children were moderate ASDs, and 9 children were severe ASDs. An additional 35 healthy children (16 females and 19 males) with mean age of $5.4 \pm 2.4$ years were served as a control group. Comparison between the two studied groups according to demographic data is shown in Table 1.

No significant differences were found between groups as regards the anthropometric measurements. Hemoglobin concentration was significantly lower in ASD group $(p=0.003)$, but no significant differences were found in other hematological parameters as shown in Table 2.

Table 3 shows that levels of IL-1ß, IL- 8 , and TNF- $\alpha$ were significantly higher in children with ASD compared with those of controls. In addition, the mean level of thioredoxine in children with ASD was significantly higher as compared with that of controls $(170.4 \pm 54.2$ and $76.9 \pm 24.8 \mathrm{pg} / \mathrm{mL}$ respectively $p<0.001)$.

We then examined whether there were associations between cytokine levels and the severity of clinical manifestations; according to CARS classification of severity, patients were divided into 3 subgroups: mild, moderate, and severe. Comparison of thioredoxine and cytokines levels between ASD subgroups is shown in Table 4. No significant differences were found between subgroups.

\section{Discussion}

Evidence is accumulated that ASD is interrelated with certain physiological abnormalities, including oxidative stress and immune dysregulation [26].

Research suggests the involvement of cytokines in neurodevelopment, beside their effect in some neurological functions, including cognition and memory [18, 27]. Hence, disturbances within cytokine levels may result in multiple neurological outcomes related to ASD [28].

In addition, disturbance in the levels of oxidative stress may be relevant to the pathophysiology of ASD [6].

The aim of the present study was to assess the state of immune dysregulation, as estimated from the serum levels of some cytokine (IL-1 $\beta$, IL- 8 , TNF- $\alpha$ ) and thioredoxin, as an indicator of oxidative stress in children with ASD.

In this work, it was found that $68.6 \%$ of autistic patients were males, and male to female ratio was 2.19:1 respectively. This finding is corresponding to previously reported ratios [29]. 
Table 1 Demographic and clinical characteristics data of autism spectrum disorders (ASD) and control children

\begin{tabular}{|c|c|c|c|}
\hline Characteristic & ASD & Controls & $p$ \\
\hline Number of children & 35 & 35 & NS \\
\hline Age (year) (mean $\pm S D)$ & $4.7 \pm 2.4$ & $5.4 \pm 2.4$ & NS \\
\hline \multicolumn{4}{|l|}{ Sex } \\
\hline Males & 24 & 19 & \multirow[t]{2}{*}{ NS } \\
\hline Females & 11 & 16 & \\
\hline \multicolumn{4}{|l|}{ Residence } \\
\hline Urban & 29 & 24 & \multirow[t]{2}{*}{ NS } \\
\hline Rural & 6 & 11 & \\
\hline Paternal age at birth (year) (mean \pm SD) & $32.5 \pm 6.8$ & $31.3 \pm 3.8$ & NS \\
\hline Maternal age at birth (year) (mean \pm SD) & $28.2 \pm 5.02$ & $27.9 \pm 3.7$ & NS \\
\hline \multicolumn{3}{|l|}{ Prematurity } & \multirow[t]{3}{*}{ NS } \\
\hline Yes & 5 & 3 & \\
\hline No & 30 & 32 & \\
\hline Groups of ASD according to CARS & \multicolumn{3}{|l|}{$n($ mean $\pm S D)$} \\
\hline Mild $(30-<33)$ & $10(30.6 \pm 0.3)$ & N/A & \multirow[t]{3}{*}{$<0.001^{*}$} \\
\hline Moderate $(33-<37)$ & $16(34.6 \pm 0.8)$ & N/A & \\
\hline Severe (37-60) & $9(44.2 \pm 3.6)$ & N/A & \\
\hline
\end{tabular}

NS non-significant, $N / A$ not applicable, CARS childhood autism rating scale

${ }^{*}$ significant $p$ value $(p \leq 0.05)$

Results also revealed that residence in urban areas is not a risk factor of autism. These results are in accordance to the study of [30]. However, [31] stated that patients with ASD were more common in urban areas.

The current study showed that none of maternal or paternal age was a risk factor for ASD. This was previously proved by [30]. However, [32] illustrated an association between advancing paternal age and risk of ASD. On the other hand, [33] showed that high maternal age (> 35 years) may be a predisposing factor for ASD. Moreover, [34] revealed that the risk of ASD was greater with increase of either paternal or maternal age.

Our ASD patients were anemic as their mean level of hemoglobin was $(10.37 \pm 1.24 \mathrm{~g} / \mathrm{dl})$ compared with $(11.55 \pm 1.27 \mathrm{~g} / \mathrm{dl})$ in healthy children. This finding was in accordance with results of [35] that revealed an association between ASDS and iron deficiency anemia.

In addition, [36] reported a frequency of $28.07 \%$ of children with ASDs having anemia based on low hemoglobin concentrations; they explained this finding by the high prevalence of diminished iron intake in those children, due to the associated feeding difficulties and food selectivity.

In the present study, the serum levels of IL-1 $\beta$, IL-8, and TNF- $\alpha$ were significantly higher in patients with ASD in comparison to control subjects $(p=<0.001,0.04$, $<0.001$ respectively).

As several pro-inflammatory cytokines are known to be produced by adipose tissue and the serum levels of those cytokines have been correlated with parameters of

Table 2 Comparison between the two studied groups according to anthropometric and hematological parameters

\begin{tabular}{llll}
\hline Parameter & ASD (mean \pm SD) & Controls (mean \pm SD) & $p$ \\
\hline WAZ & $0.067 \pm 0.47$ & $0.11 \pm 0.5$ & NS \\
HAZ & $0.09 \pm 0.4$ & $0.1 \pm 0.5$ & NS \\
BAZ & $0.02 \pm 0.6$ & $0.1 \pm 0.9$ & NS \\
Hb $(\mathrm{g} / \mathrm{dl})$ & $10.37 \pm 1.24$ & $11.55 \pm 1.27$ & $<0.001^{*}$ \\
RBCs $\left(\times 10^{6} / \mathrm{mm}^{3}\right)$ & $4.81 \pm 0.5$ & $4.73 \pm 0.4$ & $\mathrm{NS}$ \\
WBCs $\left(\times 10^{3} / \mathrm{mm}^{3}\right)$ & $7.87 \pm 2.26$ & $7.77 \pm 2.58$ & $\mathrm{NS}$ \\
Platelets $\left(\times 10^{3} / \mathrm{mm}^{3}\right)$ & $338.6 \pm 71.5$ & $311.5 \pm 72.2$ & $\mathrm{NS}$ \\
\hline
\end{tabular}

WAZ weight-for-age Z-score, HAZ height-for-age Z-score, BMI body mass index, $H b$ hemoglobin, RBCs red blood cell count, WBCs white blood cell count, NS non-significant

${ }^{*}$ significant $p$ value $(p \leq 0.05)$ 
Table 3 Inflammatory cytokines and thioredoxin levels in the two studied groups

\begin{tabular}{llll}
\hline Parameter & ASD $($ mean $\pm S D)$ & Controls $($ mean $\pm S D)$ & $p$ \\
\hline Interleukin-1ß $(\mathrm{pg} / \mathrm{ml})$ & $54.2 \pm 22.3$ & $21.66 \pm 11.3$ & $<0.001^{*}$ \\
Interleukin 8 $(\mathrm{pg} / \mathrm{ml})$ & $59.4 \pm 34.4$ & $45.3 \pm 18.5$ & $0.04^{*}$ \\
Tumor necrosis factor-a $(\mathrm{pg} / \mathrm{ml})$ & $344.29 \pm 51.6$ & $285.5 \pm 64.6$ & $<0.001^{*}$ \\
Thioredoxine $(\mathrm{pg} / \mathrm{ml})$ & $170.4 \pm 54.2$ & $76.9 \pm 24.8$ & $<0.001^{*}$ \\
\hline
\end{tabular}

${ }^{*}$ significant $p$ value $(p \leq 0.05)$

obesity [37]; therefore, we measured the weight and height of all the participants and body mass index (BMI) was calculated.

Our results showed no significant difference between the two groups as regard WAZ, HAZ, and BAZ. Thus, it is likely that the elevations in serum levels of those cytokines were significantly associated with the diagnosis of ASD.

In accordance with our results, [38] indicated that the levels of many immune proteins in plasma, including cytokines, are altered in ASD. Also, [14] reported high plasma concentrations of pro-inflammatory cytokines, such as IL- $1 \beta$ and IL- 8 in autistic patients. The findings of elevated plasma levels of IL-8, a chemoattractant cytokine of important role in inflammation process, coincide to IL-8 elevation reported in the brain and cerebrospinal fluid (CSF) in ASD [39].

Moreover, [40] reported higher levels of IL-8 without similar increases in IL- $1 \beta$ or TNF- $\alpha$. They suggested that IL-8 is the most sensitive pro-inflammatory mediator in autistic.

On the other hand, [41] found increased TNF- $\alpha$ in the cerebrospinal fluid of autistics.

The disturbed immunity was further evidenced by increased levels of pro-inflammatory cytokines in brain tissue of autistics $[11,25,42]$.

In addition, histological changes of microglia cells that were found in different brain areas provide an evidence for activation of the immune system [43]. These histological changes were supported by neuroimaging studies as well as by [44].

Synaptic dysfunction is consistently thought to be the main underlying mechanism of ASD. Pro-inflammatory mediators, including cytokines, might be involved in different synaptic processes, such as long-term potentiation
(LTP), that is involved in synaptic plasticity in learning and memory processes [45]; cytokines, such as IL-18, IL$1 \beta$, and TNF-a, act on many molecular components of LTP in variable fashions [46].

Our results revealed that none of the analytic serum levels of cytokines were correlated with the severity of autistic symptoms. So it was suggested that the elevation of cytokines observed in this study may represent an abnormal steady-state immune response in subjects with ASD.

Oxidative damage is thought to play a central role in the pathogenesis of autism [47]. Different evidences supported the relation between oxidative stress and ASD. For instance, the evidence of diminished antioxidant capacity besides enhanced production of oxidative stress biomarkers that has been found in children with ASD $[48,49]$. Previous reports have shown that the serum thioredoxin level is a good indicator of oxidative stress [50].

A major concern of this study was to assess the serum level of thioredoxin in children with autism as compared with that of the controls, and it was interesting to find that there was a highly statistically significant increase in the mean serum level of thioredoxin in ASD group as compared with that of the control group $(p=0.001)$.

These results were in agreement with a study done by [6] who found that the median serum thioredoxin levels were significantly higher in children with ASD as compared with typically developing children.

\section{Conclusions}

Overall, the present study provides support for the idea that physiological abnormalities such as oxidative stress and immune dysfunction, may contribute in the etiopathogenesis of ASD. The available data indicate a

Table 4 The mean serum level of cytokines and thioredoxine in different groups of children with ASD

\begin{tabular}{lllll}
\hline Parameter & $\begin{array}{l}\text { Mild ASDs }(n=10) \\
(\operatorname{mean} \pm \text { SD })\end{array}$ & $\begin{array}{l}\text { Moderate ASD }(n=16) \\
(\text { mean } \pm \text { SD })\end{array}$ & Severe ASDs $(n=9)($ mean \pm SD) & $p$ \\
\hline Interleukin-1B $(\mathrm{pg} / \mathrm{ml})$ & $65.6 \pm 37.5$ & $51.3 \pm 10.8$ & $46.8 \pm 8.2$ & NS \\
Interleukin 8 $(\mathrm{pg} / \mathrm{ml})$ & $62.7 \pm 29.2$ & $59.9 \pm 26.5$ & $54.8 \pm 52.2$ & $\mathrm{NS}$ \\
Tumor necrosis factor-a $(\mathrm{pg} / \mathrm{ml})$ & $336.5 \pm 56.5$ & $344.7 \pm 51.7$ & $177.8 \pm 42.6$ & $\mathrm{NS}$ \\
Thioredoxine $(\mathrm{pg} / \mathrm{ml})$ & $168.3 \pm 57.1$ & $167.5 \pm 60.7$ & & NS \\
\hline
\end{tabular}


possible relationship between cytokine alterations and autism. However, systematic investigations of the immunological factors in autism are needed and will provide a better understanding of the underlying mechanisms responsible for the pathogenesis of autism.

\section{Abbreviations}

ASD: Autism spectrum disorders; BAZ: BMI-Z-score; BMI: Body mass index; CARs: Childhood autism rating scale; CSF: Cerebrospinal fluid; DSM-5: The Diagnostic and Statistical Manual of Mental Disorders, 5th edition; HAZ: Heightfor-age Z-score; HRP: Horseradish peroxidase; IFNץ: Interferon gamma; IL1B: Interleukin-1 B; LTP: Long-term potentiation; OD: Optical density; $p$ : Probability values; SPSS: Statistical package for social science: TGF $\beta 1$ : Transforming growth factor $\beta 1$; TNF-a: Tumor necrosis factor alpha; Trx: Thioredoxin; WAZ: Weight-for-age Z-score

\section{Acknowledgements}

The authors would like to express their gratitude to all the participants of this study.

\section{Authors' contributions}

NAA was a major contributor in writing the manuscript, OMl provided recent references for the discussion, HAE was responsible for the lab work, MAS analyzed and interpreted the patient data, RAH performed the psychiatric assessment, and NME and BH participated in the design of the study. All authors read and approved the final manuscript.

\section{Funding}

None.

\section{Availability of data and materials}

All data generated or analyzed during this study are included in this published article and its supplementary information files.

\section{Ethics approval and consent to participate}

The study protocol was approved by the institution ethical review board (medical research ethics committee at National Research Centre, Cairo, Egypt) according to Helsinki Declaration 1975 revised in 2008.Comittee's reference number is 1453 . Written informed consent was obtained from all parents of both patients and control groups before getting them involved in the study. They were informed by the aim and potential benefits of the study.

\section{Consent for publication}

Not applicable.

\section{Competing interests}

The authors declare that they have no competing interests.

\section{Author details}

${ }^{1}$ Pediatric Department, Faculty of Medicine for Girls, Al-Azhar University, Cairo, Egypt. ${ }^{2}$ Child Health Department, National Research Centre, Cairo, Egypt. ${ }^{3}$ Medical Biochemistry Department, National Research Centre, Cairo, Egypt. ${ }^{4}$ Psychiatry Department, Faculty of Medicine for Girls, Al-Azhar University, Cairo, Egypt. ${ }^{5}$ Psychiatry Department, Faculty of Medicine, Al-Mansoura University, Mansoura, Egypt. ${ }^{6}$ Pediatric Department, Faculty of Medicine, Aswan University, Aswan, Egypt.

\section{Received: 11 February 2020 Accepted: 14 February 2020}

Published online: 04 May 2020

\section{References}

1. Chauhan A, Chauhan V (2015) Increased vulnerability to oxidative stress and mitochondrial dysfunction in autism. In: Molecular basis of autism. Springer, New York, pp 407-425

2. Wiggins LD, Baio J, Rice C (2006) Examination of the time between first evaluation and first autism spectrum diagnosis in a population- based sample. J Dev Behav Pediatr 27(2):579-587

3. Rossignol D (2012) A review of research trends in physiological abnormalities in autism spectrum disorders: immune dysregulation, inflammation, oxidative stress, mitochondrial dysfunction and environmental toxicant exposures. Mol Psychiatry 17(4):389-401

4. Lyall K, Schmidt RJ, Hertz-Picciotto I (2014) Maternal lifestyle and environmental risk factors for autism spectrum disorders. Inter J Epid 43(2): 443-464

5. Al-Gayyar M, Abdelsaid M, Matragoon S, Pillai B et al (2011) Thioredoxin interacting protein is a novel mediator of retinal inflammation and neurotoxicity. Br J Pharmacol 164(1):170-180

6. Zhang Q, Gao S, Zhao H (2015) Thioredoxin: a novel, independent diagnosis marker in children with autism. Inter J Devel Neurosc 40:92-96

7. Sweeten TL, Posey DJ, Shankar S, McDougle CJ (2004) High nitric oxide production in autistic disorder: a possible role for interferon- $\gamma$. Biol Psychiatry 55(4):434-437

8. Zimmerman AW, Jyonouchi H, Comi AM, Connors SL, Milstien S, Varsou A et al (2005) Cerebrospinal fluid and serum markers of inflammation in autism. Pediatr Neurol 33:195-201

9. Okada K, Hashimoto K, Iwata $Y$ et al (2007) Decreased serum levels of transforming growth factor- $\beta 1$ in patients with autism. Prog NeuroPsychopharmacol Biol Psychiatry 31(2):187-190

10. Enstrom A, Onore C, Hertz-Picciotto I, Hansen R, Croen L et al (2008) Detection of IL-17 and IL-23 in plasma samples of children with autism. Am J Biochem Biotechnol 4:114-120

11. Li X, Chauhan A, Sheikh AM, Patil S, Chauhan V, Li XM et al (2009) Elevated immune response in autistic children. J Neuroimmunol 207:111-116

12. Suzuki KH, Iwata K, Kameno Y, Shimmura C, Kawai S, Yoshihara Y et al (2011) Plasma cytokine profiles in subjects with high-functioning autism spectrum disorders. PLoS One 6:e20470

13. Schwarz E, Guest PC, Rahmoune H, Wang L, Levin Y et al (2011) Sex-specific serum biomarker patterns in adults with Asperger's syndrome. Mol Psychiatry 16(12):1213-1220

14. Ashwood P, Krakowiak P, Hertz-Picciotto I, Hansen RL, Pessah IN, Van de Water J (2011) Elevated plasma cytokines in autism spectrum disorders provide evidence of immune dysfunction and are associated with impaired behavioral outcome. Brain Behav Immun 25:40-45

15. Schneider H, Pitossi F, Balschun D, Wagner A, del Rey A, Besedovsky HO (1998) A neuromodulatory role of interleukin-1 beta in the hippocampus. Proc Natl Acad Sci U S A 95:7778-7783

16. Cacci E, Claasen JH, Kokaia Z (2005) Microglia-derived tumor necrosis factoralpha exaggerates death of newborn hippocampal progenitor cells in vitro. J Neurosci Res 80:789-797

17. Bernardino L, Agasse F, Silva B, Ferreira R, Grade S, Malva JO (2008) Tumor necrosis factor-alpha modulates survival, proliferation, and neuronal differentiation in neonatal subventricular zone cell cultures. Stem Cells 26: 2361-2371

18. Regulation of learning and memory by meningeal immunity: a key role for IL-4. J Exp Med 2010; 207:1067-1080

19. Goines PE, Ashwood P (2013) Cytokine dysregulation in autism spectrum disorders (ASD): possible role of the environment. Neurotoxicol Teratol 36 67-81

20. American Psychiatric Association (APA) (2013) Diagnostic and statistical manual of mental disorders, 5th edn. Author, Washington, DC

21. Schopler E, Reichler RJ, Renner BR (1988) The childhood autism rating scale (CARS). Los Angeles, West Psychol Serv

22. Geier DA, Kern JK, Geier MR (2013) A comparison of the autism treatment evaluation checklist (ATEC) and the childhood autism rating scale (CARS) for the quantitative evaluation of autism. J Ment Health Res Intellect Disabil 6: 255-267

23. Saad K, Abdel-rahman AA, Elserogy YM, Al-Atram AA et al (2016) Vitamin D status in autism spectrum disorders and the efficacy of vitamin $D$ supplementation in autistic children. Nutr Neurosci 19(8):346-351

24. WHO (2007) AnthroPlus for personal computers. Manual software for assessing growth of the world's children and adolescents, Geneva. http:// www.who.int/growthref/tools/en/

25. Kabuyama Y, Kitamura T, Yamaki J, Homma MK et al (2008) Involvement of thioredoxin reductase 1 in the regulation of redox balance and viability of rheumatoid synovial cells. Biochem Biophys Res Commun 367:491-496

26. Rossignol DA, Frye RE (2014) Evidence linking oxidative stress, mitochondria dysfunction, and inflammation in the brain of individuals with autism. Front Physiol 5:150

27. McAfoose J, Baune BT (2009) Evidence for a cytokine model of cognitive function. Neurosci Biobehav Rev 33:355-366 
28. Szachta P, Skonieczna-Żydecka K, Adler G, Karakua-Juchnowicz H, Madlani H, Ignyś I (2016) Immune related factors in pathogenesis of autism spectrum disorders. Eur Rev Med Pharmacol Sci 20(14):3060-3072

29. Duringer J, Fombonne E, Craig M (2016) No association between mycotoxin exposure and autism: a pilot case-control study in school-aged children. Toxins 8(7):224

30. El Sawy MA, Awadalla HI, Mohamed RR, Zaki OK et al (2011) Study of some environmental and genetic determinants of autism in Egyptian children. Int J Psychol Couns 3(8):130-136

31. Lai D, Tseng Y, Hou Y (2012) Gender and geographic differences in the prevalence of autism spectrum disorders in children: analysis of data from the national disability registry of Taiwan. Res Dev Disabil 33:909-915

32. Sandin S, Schendel D, Magnusson P, Hultman C et al (2016) Autism risk associated with parental age and with increasing difference in age between the parents. Mol Psychiatry 21(5):693-700

33. El-Baz F, Ismael NA, Nour Eldin SM (2011) Risk factors for autism: an Egyptian study. Egypt J Med Hum Genet 12(1):31-38

34. Idring S, Magnusson C, Lundberg M, Ek M, Rai D, Svensson AC et al (2014) Parental age and the risk of autism spectrum disorders: findings from a Swedish population-based cohort. Inter J Epidem 43(1):107-115

35. Chen M, Su T, Chen Y, Hsu JW et al (2013) Association between psychiatric disorders and iron deficiency anemia among children and adolescents: a nationwide population-based study. BMC Psych 13(1):1

36. Castro K, Marchezan J, Faccioli L, Riesgo R et al (2016) Anemia associated with autism spectrum disorder. Int J Pediat Health Care Adv 3(1):17-22

37. Fujita-Shimizu A, Suzuki K, Nakamura K, Miyachi T, Matsuzaki H et al (2010) Decreased serum levels of adiponectin in subjects with autism. Prog Neuropsychopharmacol Biol Psychiatry 34:455-458

38. Onore C, Careaga M, Ashwood P (2012) The role of immune dysfunction in the pathophysiology of autism. Brain Behav Immun 26:383-392

39. Vargas DL, Nascimbene C, Krishnan C, Zimmerman AW, Pardo CA (2005) Neuroglial activation and neuroinflammation in the brain of patients with autism. Ann Neurol 157:67-81

40. Tonhajzerova I, Ondrejka I, Mestanik M, Mikolka P, Hrtanek I, Mestanikova A et al (2015) Inflammatory activity in autism spectrum disorder. In: Respirat Health. Springer International Publishing Switzerland, pp 93-98

41. Chez MG, Dowling T, Patel PB, Khanna P, Kominsky M (2007) Elevation of tumor necrosis factor-alpha in cerebrospinal fluid of autistic children. Pediatr Neurol 36:361-365

42. Wei H, Zou H, Sheikh AM et al (2011) IL-6 is increased in the cerebellum of autistic brain and alters neural cell adhesion, migration and synaptic formation. J Neuroinflammation 8:52

43. Tetreault NA, Hakeem AY, Jiang S (2012) Microglia in the cerebral cortex in autism. J Autism Dev Disord 42:2569-2572

44. Suzuki K, Sugihara G, Ouchi Y, Nakamura K, Futatsubashi M, Takebayashi K et al (2013) Microglial activation in young adults with autism spectrum disorder. JAMA Psychiatry 70:49-58

45. Di Filippo M, Chiasserini D, Gardoni F, Viviani B, Tozzi A, Giampa C (2013) Effects of central and peripheral inflammation on hippocampal synaptic plasticity. Neurobiol Dis 52:229-236

46. Canitano R, Scandurra V (2014) Glutamatergic agents in autism spectrum disorders: current trends. Res Autism Spectr Disord 8:255-265

47. Feng C, Chen Y, Pan J, Yang A et al (2017) Redox proteomic identification of carbonylated proteins in autism plasma: insight into oxidative stress and its related biomarkers in autism. Clin Proteomics 14(1):2

48. Al-Yafee Y, Al-Ayadhi L, Haq S, El-Ansary A (2011) Novel metabolic biomarkers related to sulfur-dependent detoxification pathways in autistic patients of Saudi Arabia. BMC Neurol 11(1):1

49. Whayne TF, Parinandi N, Maulik N (2015) Thioredoxins in cardiovascular disease 1. Can J Physiol Pharmacol 93(11):903911

50. Zhang X, Xiu M, Wang F, Qi LY et al (2009) The novel oxidative stress marker thioredoxin is increased in first-episode schizophrenic patients. Schizophr Res 113(2):151-157

\section{Publisher's Note}

Springer Nature remains neutral with regard to jurisdictional claims in published maps and institutional affiliations.

\section{Submit your manuscript to a SpringerOpen ${ }^{\circ}$ journal and benefit from:}

- Convenient online submission

- Rigorous peer review

- Open access: articles freely available online

- High visibility within the field

- Retaining the copyright to your article

Submit your next manuscript at $\boldsymbol{\nabla}$ springeropen.com 